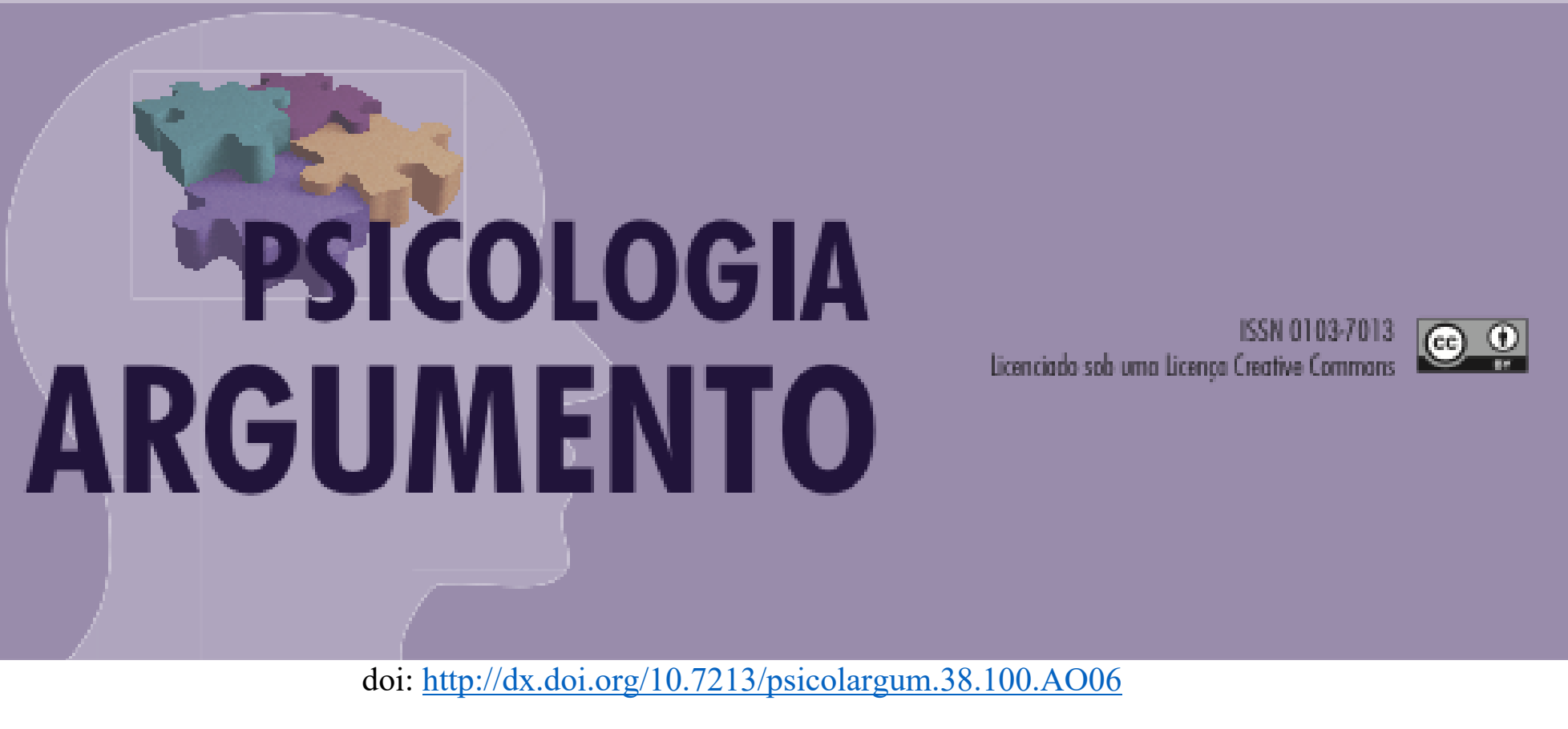

\title{
Significados de morte e morrer para profissionais de unidade de terapia intensiva
}

Meanings of death and dying for intensive care unit professionals

Significado de muerte y morir para profesionales de la unidad de cuidados intensivos

Queli Nascimento Santos

Doutoranda em Psicologia da Universidade Federal da Bahia (UFBA).

Email: quelinsantos@yahoo.com.br https://orcid.org/0000-0002-4537-5661

Lauro Antonio Porto

Doutor. Docente do Programa de Pós-Graduação em Saúde, Ambiente e Trabalho da UFBA.

Email: lauroporto@uol.com.br https://orcid.org/0000-0001-9336-7845

Claudia Bacelar Batista

Doutora. Docente do Programa de Pós-Graduação em Saúde, Ambiente e Trabalho da UFBA.

Email: claudia_bacelar@hotmail.com https://orcid.org/0000-0003-1925-8813

\section{Resumo}

Ao longo do tempo, morte e morrer foram processos transferidos para o espaço do hospital e serviços de saúde especializados, como as unidades de terapia intensiva (UTI). Essa transição levou ao profissional da equipe de saúde a convivência constante com tais fenômenos. Nesse contexto, o presente estudo objetivou compreender como profissionais de uma unidade de terapia intensiva vivenciam a morte e o processo de morrer em seu cotidiano de trabalho, através dos 
significados que atribuem a esses fenômenos. Tratou-se de uma pesquisa qualitativa que utilizou como recursos empíricos as observações de campo e entrevista semiestruturada. Participaram do estudo 25 profissionais pertencentes à equipe da UTI, compreendendo médicos, enfermeiros, técnicos de enfermagem, fisioterapeutas, psicólogo e auxiliar administrativo. As unidades de análise morte e morrer são apresentadas de acordo com os conteúdos relatados e cenários que projetaram a marca da experiência vivenciada, analisados com base na fenomenologia social compreensiva de Alfred Schütz. Os resultados mostraram que a experiência com a morte de pacientes na unidade de cuidados intensivos é naturalizada por meio da adaptação ao contexto, apontada como dimensão que faz parte da vida; e, com o processo de morrer, a experiência engloba maior dificuldade de enfrentamento quando profissionais e pacientes estabelecem um vínculo duradouro. Por fim, ressaltou-se a necessidade de espaços para escuta dos profissionais da assistência, que trabalham em contextos exigentes e diante de fenômenos complexos, como são morte e morrer, em busca de acolhimento para a expressão da experiência.

Palavras-chave: Morte. Atitude Frente à Morte. Unidades de Terapia Intensiva. Fenomenologia.

\begin{abstract}
Over time, the processes of death and dying have been transferred to the space of hospitals and specialized health services, such as intensive care units (ICU). This transition has led health team professionals to constantly live with these phenomena. In this context, the present study had as an objective to understand how intensive care unit professionals experience death and the process of dying in their working daily lives, by the meanings they attribute to these phenomena. It was a piece of qualitative research which used as empirical sources field observations and semistructured interviews. Twenty-five members of the ICU team took part in the study, among them were doctors, nurses, nursing technicians, physiotherapists, a psychologist, and an administrative assistant. The units of analysis death and dying are presented according to contents reported and scenarios that predicted the imprint of the experience, analyzed based on the comprehensive social phenomenology approach by Alfred Schütz. The results show that the experience on the death of patients in intensive care units have been made natural by means of adaptation to context, being identified as an aspect that is part of life; and, for the process of dying, the experience involves greater difficulty in facing it when professionals and patients establish a long-term relationship. Finally, it was highlighted the need for space for healthcare professionals, who work in demanding contexts and facing complex phenomena, such as death and dying, to be heard in search for a receptive environment for the expression of the experience.
\end{abstract}

Keywords: Death. Attitude to Death. Intensive Care Units. Phenomenology.

\title{
Resumen
}

A través del tiempo, la muerte y el morir fueron procesos trasladados al espacio de hospitales y servicios de salud especializados, como Unidades de Cuidados Intensivos (UCI). Esta transición llevó al profesional del equipo de salud a convivir constantemente con tales fenómenos. Bajo este contexto, el presente estudio tuvo como objetivo comprender cómo los profesionales de una Unidad de Cuidados Intensivos experimentan la muerte y el proceso del morir en su trabajo diario, a través de los significados que atribuyen a estos fenómenos. Esta fue una investigación cualitativa que utilizó observaciones de campo y entrevistas semiestructuradas como recursos empíricos. En el estudio participaron 25 profesionales que pertenecen al equipo de la UCI, incluidos médicos, enfermeras, técnicos de enfermería, fisioterapeutas, un psicólogo y un auxiliar administrativo. Las unidades de análisis muerte y morir se presentan de acuerdo con los contenidos y escenarios reportados que proyectaron la marca de la experiencia vivida, analizados en base a la fenomenología social comprensiva de Alfred Schütz. Los resultados mostraron que la experiencia con la muerte de pacientes en la unidad de cuidados intensivos se naturaliza mediante la adaptación al contexto, señalada como una dimensión que forma parte de la vida; $y$, con el proceso de morir, la experiencia abarca una mayor dificultad para afrontar cuando profesionales y pacientes establecen un vínculo duradero. Para culminar, se destacó la necesidad de espacios para escuchar a los profesionales de salud, que trabajan en contextos 
exigentes y ante fenómenos complejos, como la muerte y el morir, en busca de acoger la expresión de la experiencia.

Palabras clave: Muerte. Actitud Frente a la Muerte. Unidades de Cuidados Intensivos. Fenomenología

\section{Introdução}

A morte é um evento reconhecido como acontecimento natural do ciclo da vida e faz parte da capacidade humana ter consciência acerca dela. Essa afirmação permite compreender e elucidar que a morte e o processo de morrer configuram-se não apenas como eventos biológicos, mas são também processos construídos socialmente, pois envolvem a criação de simbologias que variam de acordo com o contexto histórico e cultural no qual os indivíduos estão inseridos (Ariès, 2017).

Uma visita aos aspectos históricos da sociedade ocidental permite demonstrar como eram as atitudes frente à morte e as variações que sofreram ao longo do tempo. Desse modo, pode ser inicialmente apontado o período da Idade Média, quando a morte e o morrer eram vividos como eventos comuns e próximos à comunidade, ou seja, as pessoas participavam livremente dos rituais de finitude, inclusive as crianças, tratando-se de verdadeira cerimônia pública (Ariès, 2017). Ao fimm desse período, a presença e função da Igreja Católica na sociedade geram outros ritos e símbolos, como instituição de vínculo entre o mundo dos vivos e dos mortos, bem como a representação figurativa do esqueleto e da foice a ceifar a vida humana.

Entre os séculos 17 e 18, o principal medo em relação à morte era ser enterrado vivo. Andrade (2008) afirma que o corpo social da época temia qualquer possibilidade de acordar dentro de um túmulo e, por conta disso, iniciam-se os rituais e cerimônias de velamento do cadáver, com duração superior a 48 horas. Já no século 19, a morte é encarada como uma via que possibilita o reencontro de entes queridos em algum universo espiritual, assumindo uma aura romantizada e uma perspectiva de passagem, não mais vista como finitude (Ariès, 2017; Vicensi, 2016). O progresso nas ciências, principalmente nas áreas biológicas e biomédicas, faz os hospitais criarem novos caminhos de assistência, reunindo profissionais de especialidades diversas, e a morte e o morrer passam a ocorrer nestes espaços (Andrade, 2008). 
A partir do século 20, os hospitais começam a ser vistos como locais de suportes à vida humana, em um modelo técnico-mecanicista de atenção, onde a morte passa a ser encarada como um fracasso (Andrade, 2008; Vicensi, 2016). Assim, a caricatura de esqueleto e foice é substituída pela imagem do sujeito hospitalizado, que tem o seu corpo invadido por tubos e aparelhos. A cena e as características da morte interdita, não comentada, distanciam-se cada vez mais da vivência familiar (Ariès, 2017; Menezes, 2003; Monteiro, 2015).

Diante desse conjunto de transformações, é possível referir-se ao ambiente hospitalar como o espaço em que são vivenciados diversos eventos, tais como suporte ao adoecimento, situações de estresse, momentos de superação e resiliência, bem como acompanhamento do processo de morrer e circunstâncias de morte (Santos \& Moreira, 2014). É dentro desse contexto que se encontram os trabalhadores que lidam diariamente com tais demandas: os profissionais da equipe de saúde. Os efeitos deste cenário têm implicações diretas na maneira como os profissionais encaram o seu campo de trabalho e como avaliam as questões suscitadas. A percepção individual e/ou coletiva, condutas e enfrentamentos estão intimamente entrelaçadas aos significados que atribuem a experiência de conviver com a morte e o morrer de um paciente no ambiente de trabalho.

Em setores mais específicos, como as unidades de terapia intensiva (UTI), são identificados elevados índices de sobrecarga mecânica e psicológica; convivência com a dor do outro; interferências emocionais ligadas à hospitalização; cobrança por qualificação profissional e a lida quase diária com o processo de morrer e morte, encarado não mais como parte da vida, mas como um evento a ser combatido, excluindo, dessa forma, espaços para expressão de emoções de medo, dor, frustação e luto (Casellato, 2015; Martins et al., 2009; Vicensi, 2016; Vieira \& Waischunng, 2018). Mais a mais, por ser uma assistência de alta complexidade, a terapia intensiva traz o estresse constante da gravidade de viver e lidar com a linha tênue que separa a vida e a morte (Beraldo et al., 2015; Vicensi, 2016).

A literatura tem demonstrado que no núcleo de todas essas experiências há receios, dúvidas, medos, inseguranças, frustações, normalizações, estranhezas e tensões, questões que são variadas e profundas (Araújo \& Belém, 2010; Beraldo et al., 2015; Covolan, et al. 2010; Monteiro, 2015; Vicensi, 2016). Assim, frente a este cenário, o presente estudo objetiva compreender como profissionais de uma unidade de terapia intensiva vivenciam a morte e o processo de morrer em seu cotidiano de trabalho, através 
dos significados que atribuem a esses fenômenos, revelando as repercussões desses eventos em suas vidas e atuações.

\section{Método}

Para a realização deste estudo foi utilizada a abordagem qualitativa de caráter descritivo-exploratório. A instituição hospitalar investigada é uma unidade que atende aos usuários do Sistema Único de Saúde (SUS) na Região Metropolitana de Salvador, fazendo parte da Rede Pública do Estado da Bahia.

O estudo foi realizado em um único hospital em virtude de tempo, praticidade e disponibilidade da instituição. Trata-se de um estudo com amostra por conveniência. $\mathrm{O}$ convite para a realização da pesquisa neste hospital se deu através de solicitação encaminhada ao Núcleo de Gestão do Trabalho e da Educação na Saúde e à Diretoria Geral, que permitiram a execução. O lócus da pesquisa foi a unidade de terapia intensiva desse hospital público, que conta com 10 leitos para internamento em cuidados intensivos. Há diariamente, nesta UTI, um médico plantonista, duas enfermeiras, três ou quatro técnicos de enfermagem, um fisioterapeuta, um auxiliar administrativo e, em dias alternados, um psicólogo. Em linhas gerais, o trabalho é realizado em regime de plantão, de $12 \mathrm{~h}$ ou $24 \mathrm{~h}$.

\section{Participantes}

Os sujeitos colaboradores deste estudo foram 25 profissionais pertencentes à equipe da UTI, compreendendo médicos, enfermeiros, técnicos de enfermagem, fisioterapeutas, psicólogo e auxiliar administrativo. Dos entrevistados, 21 eram mulheres e quatro homens. As idades variaram entre 25 e 58 anos.

Os critérios de elegibilidade dos profissionais foram: trabalhar neste setor, estar em plena atividade laboral e vivenciar as situações frequentes da prática laboral referidas à morte e morrer. O convite aos sujeitos deu-se após o período de observação, feito pela pesquisadora, e criação de vínculo com os profissionais, necessário, pois a pesquisadora não era integrante da equipe do hospital.

Havia livre interesse em participar do estudo ao conhecer o escopo da pesquisa e, após período de observação, foram iniciados os convites à entrevista. A partir do aceite, as entrevistas foram agendadas em conformidade com a disponibilidade de cada 
profissional. Houve recusa de três profissionais à participação no estudo. Uma entrevista não foi gravada, mas foram utilizadas as anotações feitas pela pesquisadora após o término da entrevista.

\section{Instrumentos}

O instrumento utilizado foi um roteiro semiestruturado para entrevista individual, que abordou o significado atribuído ao trabalho na UTI e à convivência com a morte e o processo de morrer no ambiente ocupacional. O roteiro de entrevista foi composto pelas seguintes questões: Como você descreve seu trabalho na UTI?; Como é a comunicação da morte nesta unidade (existe algum protocolo)?; O que você me diz sobre ter a morte e o morrer no cotidiano de trabalho?; Como você lida com a morte e o morrer dos pacientes internados nessa unidade?; Como você percebe seu colega de trabalho frente à morte e o morrer de um paciente?. Além da entrevista, a investigação utilizou o diário de campo tal como proposto por Frizzo (2010), registrando as informações permitidas pelo campo durante a observação e produzindo subsídios para compreensão e interpretação dos dados coletados.

\section{Procedimento de coleta de dados}

As entrevistas foram individuais e realizadas no local de trabalho, em espaços reservados. Foram feitas entrevistas na sala de espera, no conforto médico e no auditório do hospital, havendo algumas interrupções previstas, por motivos de intercorrências ou necessidade do profissional no setor. Os sujeitos assinaram o Termo de Consentimento Livre e Esclarecido (TCLE) e os depoimentos foram gravados e transcritos na linguagem original dos entrevistados. A pesquisadora realizou visitas pela manhã, à tarde e à noite, para contemplar todos os turnos possíveis, realizando ambientação e proximidade com os profissionais. Para a coleta empírica, a permanência na UTI se deu de abril a setembro de 2015.

\section{Aspectos éticos}

Para preservar a identidade de cada profissional e garantir o anonimato, foi adotado o critério de nomear os participantes por nomes fictícios. A ordem dos nomes segue a sequência de letras do alfabeto oficial da língua portuguesa e a cronologia das entrevistas, sendo Alice (entrevista 1) e Zilda (entrevista 25). O trabalho foi submetido 
na íntegra ao Comitê de Ética em Pesquisa da Faculdade de Medicina da Bahia (CEPFMB), respeitando os aspectos éticos conforme disposto na Resolução CNS 466/2012 (2013) que trata da ética em pesquisa envolvendo seres humanos, com parecer favorável, $\mathrm{n}^{\circ} 950.358$.

\section{Procedimento de análise de dados}

Após as leituras e releituras minuciosas, o conteúdo das entrevistas foi avaliado considerando-se divergências e convergências nos relatos, à busca do aspecto comum (Fini, 1994), elaborando-se unidades de significados sobre o vivido, que dialogam com o fenômeno investigado. O momento seguinte foi descrever e interpretar as unidades de acordo com o referencial escolhido da fenomenologia compreensiva de Alfred Schütz.

\section{Resultados e Discussão}

Os resultados mostram os significados de uma experiência compartilhada, que podem ser caracterizados como significados intersubjetivos de acordo com os pressupostos da fenomenologia compreensiva de Alfred Schütz (1979). As unidades de análise apresentam-se descritas e discutidas a seguir.

\section{A morte}

Com a repetição de mortes na UTI, ou mesmo por acompanharem a realização de reanimações ou serem informados da morte de pessoas aí internadas, os profissionais da UTI acabam considerando a morte como processo natural da vida e expressam a naturalização do acontecimento da morte fundamentados em sua condição de convivência com ela no ambiente e rotina de trabalho. Essa perspectiva da morte como processo natural que atinge a todos é ilustrada nas falas dos servidores.

Que a morte é uma coisa que todo mundo vai passar, então eu já acostumei [...] porque faz parte do trabalho, faz parte também da vida, processo natural da vida, então a gente acaba acostumando. "Isadora" (34 anos, técnica de enfermagem).

[...] eu acho que ninguém vai falar que é bom, não é bom, porque a gente tem muita perda na unidade, mas não vejo também como uma coisa ruim, porque é uma fase da vida. A morte vai acontecer para todo mundo. "Fernanda" (29 anos, enfermeira). 
Então, eu consigo entender que a morte é um processo natural da vida [...] acho que depois desses anos, eu consegui administrar em mim para não ficar triste com a morte. Consigo entender que ver a morte faz parte da vida. "Laura" (41 anos, enfermeira). É uma coisa que é uma realidade que a gente tem que encarar, faz parte do processo da vida [...] a gente sabe que já faz parte da vida. "Karina” (33 anos, técnica de enfermagem).

Entre alguns participantes, a situação de morte no ambiente de trabalho apresentase como mais complexa do que nas falas anteriores, ainda que de modo adaptativo. No entanto, aparece evidenciada a não habituação. As percepções da morte na UTI são expressas por sentimentos e reações negativas, revelando vulnerabilidade frente ao fato decorrido. E, embora apresente-se destacado esse aspecto na fala das participantes, a avaliação do fenômeno da morte na unidade de cuidados retoma a descrição de processo natural da vida:

(pausa) Não acostumei [sorri], muito dificil, a gente vê paciente, aqui, muito grave [...] a gente sempre tem uma esperança. Eu, como profissional, mesmo sabendo do prognóstico, penso assim, ainda tem aquela tristeza e também tem a esperança, né?. "Quézia" (44 anos, técnica de enfermagem).

Impotência, né, que você faz aquele trabalho todo [...]. Alguns a gente dá pra ver o prognóstico, assim, espera, mas é impotência; faz parte do ciclo da vida a morte, mas a gente não quer, jamais. "Rafaela" (33 anos, técnica de enfermagem).

À medida que os profissionais se deparam com a morte no cotidiano da UTI revelam os significados de tal experiência. Dentro de um conjunto variado de perspectivas, a naturalização da morte destaca-se como o processo delineado dentro da trajetória profissional e no espaço de atuação, dialogando com o ponto de vista pessoal. É necessário encarar esse evento no seu ambiente ocupacional e isso leva à compreensão de que, embora possa haver dificuldades, o cotidiano de trabalho vai existir na convivência com a morte de enfermos. É uma experiência que evoca a representação da morte entre aparelhos, equipamentos invasivos ao corpo e somente na presença dos profissionais da equipe de saúde: a morte interdita se instala (Ariès, 2017; Menezes, 2003; Monteiro, 2015).

Ao refletir sobre concepções de morte e morrer retratadas por estudantes e profissionais de saúde, Araújo e Belém (2010), Bernieri e Hirdes (2007) e Covolan et al. (2010) trouxeram como resultados acepções diversas. Nessas pesquisas, a compreensão que os entrevistados tinham sobre a morte nem sempre possuía um caráter interdito. Isto 
é, a finitude não se configurava permanentemente como um tabu, aquilo que se oculta ou se encobre, mas pode sê-lo. É possível dizer, dentro dessas considerações, que na atuação hospitalar, a morte é um fenômeno esperado, apontado como parte do desenvolvimento natural da vida e complexo.

O estudo de Monteiro (2015) sobre a repercussão da terminalidade na unidade de terapia intensiva resultou no reconhecimento da naturalização da morte por parte da equipe médica, através de justificativas de ordem biológica, religiosa e/ou psicológica. A morte como processo natural foi apontada quando se tratava de pessoas idosas ou com doenças crônicas graves, refletindo uma noção de que esses casos não invertem a ordem do esperado.

Em investigação com técnicos de enfermagem cuidando de pacientes terminais em UTI, Beraldo et al. (2015) expõem um caminho de naturalização que começa por uma experiência de frustração por despreparo no cuidado para a morte, transita para a aceitação da morte como fenômeno terapêutico, quando os profissionais reconhecem a morte "como um desfecho necessário para aliviar o sofrimento de um indivíduo" (p. 1017) sem evidências de chances de sobrevida, mas sem abdicar de ações de intervenção, e chega ao desenvolvimento de estratégias de enfrentamento do cuidado digno para a finitude, como manutenção de cuidados mínimos e distanciamento afetivo do paciente e da família deste.

Analisando a reação de enfermeiras, técnicas e auxiliares de enfermagem ao cuidar de recém-nascidos em processo de morte em uma unidade de terapia intensiva neonatal, Araújo e Belém (2010) descreveram a naturalização como um possível mecanismo de defesa e proteção contra o sofrimento experimentado por elas, pelo qual o processo de morte vem a ser vivenciado como algo banal, normal e rotineiro. Mas as autoras indicam que essa pode ser uma aparente aceitação da morte, encobrindo, na verdade, a falta de preparo das trabalhadoras para encararem tal circunstância.

Perspectivas atuais sobre a morte no ambiente de trabalho em saúde mostram que a construção de naturalidade da morte pode fazer parte de um modo de resgate do que se compreende como uma boa morte, modelo que está sendo defendido e retomado com a filosofia dos cuidados paliativos. O próprio doente em processo de morrer assume decisões acerca de sua vida, sofrimento e morte, auxiliado por familiares e profissionais que o acompanham nos momentos finais de vida, buscando-se uma morte com dignidade, sem o uso excessivo, desnecessário ou distorcido de procedimentos que gerem dor ou 
sofrimento. Compreende-se, deste modo, que a morte do sujeito é um evento natural, pois "a condição humana implica necessariamente sua finitude" (Menezes, 2003, p. 142).

Uma razão pela qual a morte é compreendida, na perspectiva paliativista, como processo natural deve-se ao direcionamento das ações de cuidado para seguirem princípios e metas que respeitem a autonomia e as necessidades do paciente (Santana, et al., 2012). Fora desse escopo, tal naturalização é tratada como negação dos acontecimentos e afastamento devidos às atuações orientadas à luta incessante pela manutenção da vida ou ao enfrentamento de eventos não normativos, como a morte de crianças (Araújo \& Belém, 2010; Vicensi, 2016).

Na UTI em estudo, como uma espiral de preparação e experiência ao longo do tempo de trabalho, nesse e em outros espaços, o significado da experiência com a morte é permeado pela naturalização adaptada. A noção de naturalização trazida na abordagem paliativa ainda não é um princípio na condução da atividade desses trabalhadores da unidade. Isto porque, por estarem na UTI, usam investimentos terapêuticos, como medicações e intubações nos pacientes com estados graves de saúde, na tentativa de recuperação e/ou prolongamento da vida, sem a devida reflexão sobre o real sofrimento ocasionado por tais procedimentos. Assim, é possível que a inserção dos cuidados paliativos em unidades intensivas, como essa, ajude a associar assistência, cuidado, cura e investimentos terapêuticos necessários.

O sentido de naturalização da morte demonstrado nos relatos da equipe é que, doravante, a morte é um fato a ser encarado no local de trabalho. É um evento possível de ocorrência e manejo, porque é rotineiro e faz parte da vida de qualquer pessoa. Isso demonstra que a naturalização da morte neste local, sem dúvidas, possibilita aos trabalhadores encararem tal evento e seguirem trabalhando. No entanto, indica também a necessidade de cuidado com os trabalhadores, com um olhar atento a modos de proteção que possam camuflar seus reais sentimentos.

Para Schütz (1974), esses aspectos são referentes à atuação dos sujeitos no mundo da vida, mundo que é cenário e objeto de ações e interações, e que conduz o indivíduo a constantes mudanças e alterações no contexto das suas atividades. De acordo com a fenomenologia social compreensiva, é possível realizar essas determinações através da relação que os sujeitos estabelecem com as coisas do mundo e com seus semelhantes. As coisas do mundo oferecem resistências que podem ser superadas ou conformadas. Com relação às coisas, as falas revelam o interjogo entre as dificuldades da convivência com a 
morte e também seus ajustes. Com os semelhantes, aparece o processo de adaptação ao fenômeno da morte, porque todos os trabalhadores enfrentam a mesma situação na UTI. Além disso, os profissionais configuram a passagem do tempo como uma aliada, que os ajuda a considerar a morte como atributo do contexto de trabalho, permanente e real.

Outra consideração encontrada diante desse aspecto de naturalizar a morte é quando a questão central recai sobre a mecanização do fazer frente ao paciente que morre e requer assistência da equipe. A mecanização pode desumanizar o trabalho e objetificar a relação do profissional com o paciente, em específico, com aquele que está morrendo (Andrade, 2008). Nesta UTI constata-se a mecanização nas seguintes declarações:

[...] vai aquela coisa mais mecânica mesmo. Acho que o trabalho da UTI tem um pouco disso, de ser meio mecânico. "Caio" (31 anos, psicólogo).

Complementando, uma colega de trabalho afirma:

[...] geralmente é uma coisa muito mecânica, então assim, você faz o que tem que ser feito e o sentimento real não tem. "Nivia" (33 anos, enfermeira).

Além dessas falas, a menção ao trabalho mecanizado, que objetifica a relação com o paciente frente à morte nesta UTI, também se fez presente em uma conversa entre a pesquisadora e um médico da equipe, quando este afirma que para um médico sem vínculo institucional formal, às vezes, o paciente se torna uma "coisa", o que remete a um tema investigado por Marsden (1992).

Registro no diário de campo: após a entrevista com um médico, ele questiona se existirá alguma correlação entre vínculo empregatício e repercussões na morte. Ele diz que deveria ser feita, pois acha que alguém com vínculo estatutário ou que tem pretensões de uma carreira com estabilidade, vai estar mais presente no hospital para acompanhar o paciente e terá mais "agonia" com a morte de um paciente, do que quem vê o paciente poucas vezes, como é o caso dos médicos dessa unidade. O médico diz que às vezes, por conta disso, o paciente se torna uma "coisa" para o profissional de medicina. Ele afirma haver a existência da "coisificação" na UTI e pareceu pensar sobre isso, não dizendo mais nada.

De acordo com Menezes (2004), a prática da medicina mudou tanto ao longo dos tempos que chegou ao ponto de fragmentar a dinâmica existente entre profissional e paciente, tendo como característica, a "objetificação da pessoa do paciente" (p. 36). Assim, é possível reconhecer a noção de coisificação embasando as atividades das 
diferentes categorias profissionais, no bojo de um trabalho mecanizado e de objetificação do paciente.

Embora não fosse uma postura unânime, essa evidência requer pensar ações de trabalho que vêm sendo protagonizadas dentro desta unidade. Justifica-se também afirmar que isso acontece quando alguns trabalhadores acabam se tornando exclusivamente tecnicistas, ancorados pela infraestrutura de alta tecnologia presente nas UTIs, que, ao mesmo tempo, afasta o profissional dos sujeitos envolvidos no processo de hospitalização.

Sob a perspectiva da análise social compreensiva de Alfred Schütz (1979), a noção de significados atribuídos por sujeitos às suas experiências dentro de um ambiente social comum confere relevância ao vivido. Como um mundo intersubjetivo compartilhado, a esfera da vida cotidiana da UTI desse hospital aparece atribuindo à morte os seguintes significados: a morte é concebida como uma condição na rotina de trabalho e evento que faz parte da vida. Portanto, os componentes centrais das declarações e ações são a naturalização e a cotidianidade. A mecanização não é um aspecto comum, embora esteja presente, devendo ser considerada, pois se constitui como uma ação realizada. Esta, em especial, precisa ser alvo de avaliação e reflexão, uma vez que pode fazer os profissionais esquecerem que o foco de intervenção na assistência é o humano e não um objeto a ser manipulado.

Atuando na análise compreensiva sobre fenômenos humanos, junto com Schütz, Capalbo (1979) admite que condutas apresentadas na vivência comum entre sujeitos podem se transformar em condições estáveis que consolidam determinados aspectos como funções, papéis sociais ou comportamentos institucionais, aceitos e admitidos por um grupo. Deste modo, como um comportamento institucional, a morte naturalizada transparece no ambiente desta UTI, sendo aceita pela maioria de seus trabalhadores. Essa naturalização seria plenamente saudável caso os profissionais a vissem como sugere a perspectiva de cuidado nos princípios paliativos, contudo, ainda funciona como aspecto defensivo de se adaptar para continuar.

O resultado dessa unidade de análise sugere que o fato de a morte estar no dia a dia desse trabalho contribui para que os profissionais descrevam a situação como um evento a encarar e reorganizem sua atuação de modo a um melhor enfrentamento. Considera-se, assim, que os trabalhadores da equipe multiprofissional desta UTI se voltam para a morte no setor, como uma característica do modus operandi. 


\section{O morrer}

Os profissionais desse estudo compreendem que o objetivo de sua unidade é tratar pacientes em risco, mas que sejam capazes de se recuperar e sobreviver. Contudo, muitas vezes, não conseguem realizar esse propósito devido à condição limítrofe em que são encaminhados os pacientes. Assim, o espaço ocupacional funciona como setor de suporte final, cabendo ao intensivista lidar com essa situação.

Diante das circunstâncias do processo de morrer, os profissionais revelaram diversas reações e sentimentos, tais como lamentação, pesar e dificuldades encaradas. Nas cenas presenciadas durante a observação, algumas manifestações foram anotadas no diário de campo.

Registro no diário de campo 1: a pesquisadora conversa com os trabalhadores na copa da UTI. Uma profissional referiu que tinha vontade de chorar só de pensar em um paciente específico, hospitalizado na unidade havia alguns meses e sem indicação de alta devido à dependência total aos aparelhos. Registro no diário de campo 2: na bancada conhecida como posto de enfermagem, a pesquisadora ouve informalmente, mas referenciada para sua escuta, quando uma trabalhadora menciona, com os óculos embaçados, os momentos em que prestou assistência a um paciente, com quem brincou e conversou assiduamente, e que veio a morrer na UTI. Ele permaneceu por determinado período internado, entre idas e vindas, para fazer hemodiálise (nessa unidade há um leito usado para essa finalidade), até sua morte no setor.

Uma intensivista sintetizou a complexidade de estar frente a essa situação na seguinte declaração:

Acompanhar o processo de morrer eu acho que é mais difícil do que lidar com a morte em si. "Giovana" (28 anos, enfermeira).

A essas verbalizações integram-se outros depoimentos dos profissionais desta UTI que marcam a dificuldade do acompanhamento:

Isso (acompanhar) para o profissional é muito desgastante e decepcionante [...] porque aqui a gente luta tanto pelo paciente. O trabalho é braçal e psicológico, e no fim esse paciente vai a óbito [...] pegamos muitas histórias de vida que terminam aqui. "Eduardo" (43 anos, técnico de enfermagem).

[...] quanto mais você convive com um paciente, mais você tem aquele vínculo e quanto menos você convive é menor o apego. É que nem o amor. Dizem que quanto mais você convive com a pessoa, mais você gosta dela. Como amor de filho, amor de mãe, então, quanto mais você convive com o paciente, mais vínculo você cria e quanto menos você convive não é tanto apego. "Karina" (33 anos, técnica de enfermagem). 
Às vezes a gente se apega mais ao paciente quando ele tem muito tempo na UTI, de certa forma, às vezes a gente acaba se envolvendo e se emocionando [...] porque a gente acaba conhecendo o histórico do paciente, acaba vendo a luta dele para sobreviver. "Isadora" (34 anos, técnica de enfermagem).

[...] a exemplo de uma que teve aqui e ficou quatro meses com a gente, a gente sentiu um pouco mais quando ela foi a óbito, porque era uma paciente que a gente lutou bastante pela vida dela, mas quando são pacientes que tem um, dois dias de UTI, a gente acaba não pegando tanto a questão sentimental. "Úrsula" (29 anos, fisioterapeuta).

Com base nessas falas e em outras declarações dos profissionais, é possível ter-se uma compreensão de suas experiências na convivência com pacientes no período final de suas vidas. O acompanhamento no processo de morrer nesta UTI caracterizou-se a partir do estabelecimento de vínculos com o paciente e do conhecimento de suas histórias de vida, já que o profissional não cria uma conexão com o paciente com pouco tempo de hospitalização. Nessa unidade, o que define o paciente entrando em processo de morrer é sinalizado em um "prognóstico reservado", que o enfermo recebe devido a suas condições e características clínicas.

O mau prognóstico é indicativo de uma morte esperada, breve ou longa, mas que certamente ocorrerá dentro desse espaço de trabalho. Diante disso, a atitude de preparação e a sensação de desgaste entre o grupo de profissionais fazem-se notadas, porque o paciente que vai morrer é aquele com quem estabeleceram uma convivência e partilharam momentos de sua história de vida e, agora, de sua finitude. Assim, preparar-se para uma possível perda do paciente que apresenta iminência de morte é uma forma reconhecida por esse grupo de trabalhadores ao lidar com a situação-limite.

Quando relatam e expressam essas condições, os profissionais mostram que, sendo o processo de morrer um acompanhamento por um período de tempo, estar frente a essa situação não é simples de vivenciar. Isto pode estar vinculado ao fato de nessa ocasião ser possível nascer uma interação entre profissional e paciente, ou seja, uma relação duradoura entre estes sujeitos, estabelecendo um convívio e um laço afetivo. Os termos que marcam a experiência de acompanhar o processo de morrer, nessa unidade de terapia intensiva, podem ser destacados como preparação e envolvimento.

As características apresentadas e reveladas pelos profissionais podem ser entendidas dentro de uma configuração denominada luto antecipatório, ou seja, um período que possibilita elaborar uma experiência de convivência próxima da morte (Fonseca, 2004). O luto representa uma reação normal e esperada diante de qualquer 
perda porque acontece frente aos rompimentos de vínculos afetivos (Cunha, 2012). Essa é a tese geral da teoria do apego de John Bowlby (1980) que descreve sobre a propensão dos seres humanos, em qualquer fase do ciclo vital, marcadamente na infância, a criarem laços de afeto, e como ser possível explicar sofrimentos emocionais ocasionados por perdas e separações desses vínculos. Esse comportamento de ligação é caracterizado pela tendência de proximidade entre pessoas e origina muitas reações humanas durante a formação, manutenção e rompimento de laços afetivos (Bowlby, 1980; Cunha, 2012).

O luto não ocorre tão somente diante de uma perda concreta, ou seja, em decorrência de uma morte real. O luto surge também de forma antecipada, levando os indivíduos a se prepararem progressivamente para o evento da morte (Rando, 2000). Nessa unidade, o luto antecipatório tem início com o mau prognóstico que o paciente recebe e caminha em um contínuo até a concretização da morte, levando os profissionais a apresentarem respostas cognitivas, emocionais e comportamentais antes da ocorrência da morte.

De acordo com Casellato (2015), existem componentes específicos em um processo de luto antecipatório - o significado da experiência da perda e a ansiedade de separação - que podem se tornar onerosos aos profissionais quando estes não encontram espaço adequado para o processo de elaboração. É preciso lembrar que a ansiedade de separação é um termo advindo dos estudos de Bowlby sobre a formação de apego e o rompimento de vínculos. Há muitas facetas no luto antecipatório, destacando-se tanto as dificuldades em ressignificar a perda processual quanto este ser um período permitido para oportunizar o fechamento de ciclos e alinhamento de situações inacabadas (Casellato, 2015; Monteiro, 2015). A função primordial do luto antecipatório é permitir a reorganização de recursos emocionais durante o processo de morrer e no enfrentamento da perda (Monteiro, 2015).

Esse processo não se limita ao paciente e sua família, estando presente também entre os profissionais de saúde. A falta de espaço para reconhecer e cuidar desses aspectos tem como consequência a maior possibilidade de um luto mal elaborado, inibido ou restrito, quando o ambiente ocupacional os obriga a se depararem com a própria mortalidade (Medeiros \& Lustosa, 2011; Vicensi, 2016; Vieira \& Waischunng, 2018). Na construção de uma rede relacional, a perda que ocorre gradualmente apresenta tanto o desejo de descanso quanto a necessidade de encarar os limites humanos frente à terminalidade, como exemplificados em: 
[...] então foi melhor assim, para a pessoa sofrer menos. "Alice" (52 anos, técnica administrativa).

[...] tem pacientes numa fase tão crítica que a gente fala que bom, no sentido de dizer que ele descansou, estava sofrendo tanto. "Zilda" (33 anos, fisioterapeuta).

[...] você não pode se apegar ao paciente como se fosse um ente seu, porque uma hora que você investe no paciente e ele não conseguiu atingir a meta que você queria,o paciente vai a óbito, de repente você desaba. "Yasmin" (46 anos, técnica de enfermagem).

Em revisão sistemática da literatura brasileira, Marques et al. (2011) recolheram evidências de que o tempo de permanência do paciente na UTI e o vínculo criado com o mesmo estão relacionados com o surgimento de uma variedade de sentimentos, como angústia, medo, fracasso e aflição frente ao processo de morrer que acompanham. Considerações análogas são apresentadas no estudo de Neri e Marinho (2010). As autoras evidenciam falas de profissionais da equipe que se encontram ligadas ao sofrimento presente durante o acompanhamento de pacientes no processo de morrer, na razão especial de não poder mais curar. Ponderam, nesse sentido, que o espaço de discussão ofertado pelo grupo Balint-Paidéia, possibilitam o desenvolvimento da capacidade para lidar com os afetos, bem como competência para avaliar sua conduta e intervir adequadamente em meio a vivência de questões complexas.

Em se tratando da vivência com o processo de morrer na UTI pesquisada, repercussões próximas aos outros estudos revelam-se como factíveis. Na possibilidade de estabelecer alguma relação mais duradoura com o paciente, podendo conhecê-lo frente a suas necessidades de adoecimento e história de vida, o intensivista remonta a sua própria existência e limitações humanas. Identifica-se com o sujeito exposto e pode se supor em seu lugar, vir a passar por condição de enfermidade semelhante, ou qualquer outro risco, como ocorre a seu paciente. Há sensação de impotência frente à morte, ao morrer, a sua própria finitude.

Para Cunha (2012), o processo de enlutamento ainda não é um modo reconhecido pelo trabalhador da saúde e há pouco espaço para sua expressão no ambiente hospitalar. Como um processo, a falta de expressividade para o luto da equipe de cuidados intensivos, ou hospitalares de modo geral, no contato persistente com pacientes a morrer, pode predispor a manifestações somáticas e psíquicas negativas, futuramente danosas aos trabalhadores se não forem cuidadas. 
É preciso dizer que nem sempre dentro da UTI os profissionais conseguem estabelecer uma relação recíproca com o paciente que acompanham, pois alguns enfermos vão piorando seus estados clínicos, tornando-se não responsivos. No entanto, foi com eles que estiveram em interação até isso não ser mais possível, restando apenas assisti-los diante do avanço da doença e/ou gravidade do caso.

Aos padrões apresentados na unidade de análise é necessário considerar, de modo particular, uma acepção trazida por Schütz, denominada de situação biograficamente determinada, que são crenças, valores, modos de agir e pensar de cada indivíduo. Esse constructo implica levar em conta que as experiências do sujeito, acumuladas na sua história pessoal, influenciam a maneira como cada um interpreta a realidade e como se apodera do espaço para assim definir a realidade que encontra (Schütz, 1979). Dessa concepção individual surge a possibilidade da análise sobre a dimensão coletiva, pois é no universo da significação intersubjetiva que se cria e se compreende o cenário social (Schütz, 1974).

Assim, referindo-se ao processo de morrer, no mundo cotidiano desta UTI, os entrevistados demonstram que acompanhar o paciente diante da terminalidade apresentase como difícil, triste e desgastante quando um vínculo fora anteriormente estabelecido. Aquilo em que acreditam, que imaginam e a forma como agem, aspectos de uma situação biograficamente determinada, apresentam, diante dessa experiência no modo de ação compartilhada, maneiras que lhes são comuns, ficando registrados na memória dos membros da equipe.

Além disso, na fenomenologia compreensiva, os momentos apresentados permitem dizer que os trabalhadores estabelecem uma relação face a face com os pares e com as pessoas a quem prestam assistência (Schütz, 2003). Essa orientação, face a face, indica que as pessoas estão interagindo ao mesmo momento em um tempo e espaço, podendo estabelecer relações mútuas. Há também orientações descritas como unilaterais, nas quais apenas um sujeito está consciente do outro, mas o outro não percebe ou não pode perceber. Quanto ao trabalho com o processo de morrer, os profissionais estabeleceram relações face a face com os pacientes e familiares, ora como bilaterais ora como unilaterais. Foi estando nessas interações que vínculos puderam ser estabelecidos e que, então, os profissionais trouxeram a dificuldade no enfrentamento desse morrer. $\mathrm{Na}$ circunstância de investigação, durante a realização do estudo, a pesquisadora também 
estabeleceu relações face a face com os trabalhadores, sendo possível, assim, a revelação das experiências com os fenômenos em questão.

Logo, no curso deste estudo, considera-se que os significados revelados junto ao cotidiano de trabalho com a morte e o morrer nesta UTI são inscritos não por categoria profissional, mas de elementos consensuais dentro de uma linguagem comum aos membros de uma equipe de saúde. Esses significados são fundamentais, pois tornam possível entender o modo como se configura o mundo dos que vivem em uma unidade de cuidados intensivos. O modelo teórico fenomenológico social de Schütz contribuiu para a compreensão de que as pessoas significam os fenômenos que experienciam no espaço de atuação profissional com fenômenos complexos e multivariados, mostrando que as expressões humanas são oriundas das interações com os sujeitos, no mundo social comum e em suas vivências cotidianas compartilhadas (Jesus et al., 2013; Schütz, 1979).

\section{Considerações finais}

Nesta pesquisa, o discurso dos participantes e o contexto de atuação evidenciam os aspectos ligados ao enfrentamento da morte e do morrer que permitem capturar o real estado do espaço reservado à vivência junto a esses eventos, bem como a forma de encarálos. Não se deve esquecer que a mudança da morte para o contexto hospitalar e, com ela, a do processo de morrer, tornou-a mais longínqua da convivência e, por vezes, mais célere. Restou pouco espaço para a compreensão de seus efeitos na vida íntima das pessoas, em especial, o impacto sobre profissionais de saúde, que convivem com essas condições no ambiente de trabalho.

Em geral, constata-se que os trabalhadores aprendem a naturalizar a morte, uma naturalização adaptada, dita como parte da vida, para que possam continuar atuando. Há clareza também sobre o vínculo estabelecido com o paciente na assistência ao morrer, marcado por afetações constantes e sem espaços de acolhimento. Assim, no contexto dessa unidade de cuidados intensivos, os significados atribuídos à morte e ao morrer foram revelados através dos efeitos dessa experiência na esfera ocupacional, aspectos que são apresentados por adaptação, mecanização na assistência, preparação, envolvimento e vínculo. Recomenda-se que ações sejam iniciadas pela gestão de saúde do trabalhador, tendo em vista que a adaptação compulsória diante de situações complexas e a ausência 
de espaço de escuta qualificada podem gerar impactos significativos na saúde mental dos trabalhadores de saúde.

Por fim, como limitações da pesquisa, pontua-se uma amostra não uniforme das diferentes categorias profissionais; o tempo entre a aceitação da pesquisadora na unidade como investigadora e seu acolhimento como novo membro da equipe, que pode ter levado a iniciais resistências; a amostragem por conveniência, que gera a incapacidade de fazer generalizações; e verificação da falta de profissionais que auxiliem os trabalhadores a lidarem com os fenômenos de morte e morrer, podendo o presente estudo contribuir para resolver essa ausência. $\mathrm{Na}$ literatura, há poucas pesquisas sobre significados e efeitos da vivência com a morte e o morrer na unidade de terapia intensiva na visão da equipe multi e interdisciplinar. A maior parte dos estudos é realizada com profissionais de enfermagem seguidos dos de medicina. Isso dificulta uma discussão mais atenciosa e aprofundada no diálogo entre os campos de atuação, como psicologia, fisioterapia, serviço social, nutrição, entre outros. Assim, acredita-se ser necessário promover novas investigações em outras unidades de cuidado intensivo, cujo foco seja interdisciplinar e com objetivos de suporte e cuidado ao cuidador.

A gente precisa disso [apoio], ninguém reparou nunca nisso. Infelizmente não é visto, eu nunca vi aqui. [Ninguém] nunca faz essas perguntas que vocêfez, nunca me fizeram. A gente se sente como se fosse despertado, uma coisa que às vezes a gente não fala para ninguém.

\section{Agradecimentos}

Agradeço à Fundação de Amparo à Pesquisa do Estado da Bahia (FAPESB) pelo auxílio-dissertação.

\section{Referências}

Andrade, T. A. M. (2008). Atitudes perante a morte e sentido de vida em profissionais de saúde. [Tese de doutorado, Universidade de Lisboa]. http://hdl.handle.net/10451/975

Araújo, S. A. N., \& Belém, K. F. (2010). O processo de morte na unidade de terapia intensiva neonatal. ConScientiae Saúde, 9(2), 290-299. http://www.redalyc.org/articulo.oa?id=92915260017

Ariès, P. (2017). História da morte no Ocidente: da Idade Média aos nossos dias. (Ed. especial). Nova Fronteira. 
Beraldo, L. M., Almeida, D. V. de, \& Bocchi, S. C. M. (2015). Da frustração ao enfrentamento do cuidado para a morte por técnicos de enfermagem. Revista Brasileira de Enfermagem, 68(6), 1013-1019. https://doi.org/10.1590/0034$7167.2015680603 \mathrm{i}$

Bernieri, J., \& Hirdes, A. (2007). O preparo dos acadêmicos de enfermagem brasileiros para vivenciarem o processo morte-morrer. Texto \& contexto enfermagem, 16(1), 8996. https://doi.org/10.1590/S0104-07072007000100011

Bowlby, J. (1980). Attachment and loss: loss, sadness and depression. Basic Books.

Casellato, G. (2015). O resgate da empatia: Suporte psicológico ao luto não reconhecido. Summus.

Capalbo, C. (1979). Metodologia das ciências sociais: A fenomenologia de Alfred Schütz. Antares.

Covolan, N., Corrêa, C. L., Hoffmann-Horochovski, M., \& Murata, M. (2010). Quando o vazio se instala no ser: Reflexões sobre o adoecer, morrer e a morte. Revista Bioética, $18(3)$ $561-571$.

\section{http://revistabioetica.cfm.org.br/index.php/revista_bioetica/article/view/585}

Cunha, C. R. da S. (2012). Perdendo todos os dias: sobre a possibilidade de elaboração do luto em uma equipe de saúde. [Monografia de Aprimoramento, Quatro Estações Instituto de Psicologia]. https://docplayer.com.br/14506932-Perdendo-todos-os-diassobre-a-possibilidade-de-elaboracao-do-luto-em-uma-equipe-de-saude.html

Fini, M. I. (1994). Sobre a pesquisa qualitativa em educação, que tem a fenomenologia como suporte. In M. A. V. Bicudo \& V. H. C. Espósito (Orgs.), A pesquisa qualitativa em educação: Um enfoque fenomenológico (2a ed., pp. 23-33). Unimep.

Fonseca, J. P. (2004). Luto Antecipatório. Livro Pleno.

Frizzo, K. R. (2010). Diário de Campo: reflexões epistemológicas e metodológicas. In J. C. Sarriera \& E. T. Saforcada (Orgs.), Introdução à Psicologia Comunitária: bases teóricas e metodológicas (pp. 169-187). Sulina.

Jesus, M. C. de P., Capalbo, C., Merighi, M. A. B., Oliveira, D. M. de, Tocantins, F. R., Rodrigues, B. M. R. D., \& Ciuffo, L. L. (2013). A fenomenologia social de Alfred Schütz e sua contribuição para a enfermagem. Revista da Escola de Enfermagem da USP, 47(3), 736-41. http://dx.doi.org/10.1590/S0080-623420130000300030 
Marsden, C. (1992). An ethical assessment of intensive care. International Journal of Technology Assessment in Health Care, 8(3), 408-418. https://doi.org/10.1017/S0266462300013714

Marques, F., Botelho, M. R., Matos, P., \& Waidman, M. (2011). Morte em uma unidade de terapia intensiva: A visão da equipe multidisciplinar em relação ao paciente e ao corpo. Anais do VII Encontro Internacional de Produção Científica. Cesumar. http://www.cesumar.br/prppge/pesquisa/epcc2011/anais/fernanda_ribeiro_baptista_ marques\%20(1).pdf

Martins, P. F., Nascimento Sobrinho, C. L., Silva, M. V., Pereira, N. B., Gonçalves, C. M., Rebouças, B. S., \& Cartaxo, L. A. (2009). Afastamento por doença entre trabalhadores de saúde em um hospital público do estado da Bahia. Revista Brasileira de Saúde Ocupacional, 34(120), 172-178. http://dx.doi.org/10.1590/S030376572009000200008

Medeiros, L. A., \& Lustosa, M. A. (2011). A difícil tarefa de falar sobre morte no hospital. $\begin{array}{lllll}\text { Revista } & d a & \text { SBPH, } & \text { 203-227. }\end{array}$ http://pepsic.bvsalud.org/pdf/rsbph/v14n2/v14n2a13.pdf

Menezes, R. A. (2004). Em busca da boa morte: Antropologia dos cuidados paliativos. Fiocruz, Garamond.

Menezes, R. A. (2003). Tecnologia e "Morte Natural": O morrer na contemporaneidade. Physis: Revista de Saúde Coletiva, 13(2), 129-147. https://doi.org/10.1590/S010373312003000200008

Monteiro, M. C. (2015). No palco da vida, a morte em cena: as repercussões da terminalidade em UTI para família e para equipe médica. [Tese de doutorado, Universidade Católica do Rio de Janeiro]. https://www.maxwell.vrac.pucrio.br/26557/26557.pdf

Neri, R., \& Marinho, S. (2010). Do tratamento ao cuidado: o relato de uma experiência de grupo Balint-Paidéia. In Instituto Nacional de Câncer. Comunicação de notícias dificeis: compartilhando desafios na atenção à saúde, pp. 97-106. INCA. https://abrafin.org.br/wp-content/uploads/2015/01/comunic_noticias_dificeis.pdf

Rando, T. (2000). Clinical dimensions of anticipatory mourning. Research Press. 
Santana, J. C. B., Wenceslau, D. R., Martins, F. S., Almeida, M. F. de, \& Costa, M. M. S. (2012). Cuidados paliativos nas unidades de terapia intensiva: implicações na assistência de enfermagem. Enfermagem Revista, 15(3), 327-343. http://periodicos.pucminas.br/index.php/enfermagemrevista/article/view/21101/0

Santos, R. A., \& Moreira, M. C. N. (2014). Resiliência e morte: o profissional de enfermagem frente ao cuidado de crianças e adolescentes no processo de finitude da vida. Ciência \& Saúde Coletiva, 19(12), 4869-4878. http://dx.doi.org/10.1590/1413812320141912.18862013

Schütz, A. (1974). El problema de la realidad social. Escritos I. Amorrortu.

Schütz, A. (2003). Estudios sobre teoría social. Escritos II. Amorrortu.

Schütz, A. (1979). Fundamentos da Fenomenologia. O Cenário Cognitivo do Mundo da Vida. Ação no Mundo da Vida. O Mundo das Relações Sociais. In H. Wagner (Org.), Fenomenologia e relações sociais: textos escolhidos de Alfred Schütz (pp. 51-76, 77120, 121-156, 157-237). Zahar.

Vicensi, M. do C. (2016). Reflexão sobre a morte e o morrer na UTI: a perspectiva do profissional. Revista Bioética, 24(1), 64-72. https://doi.org/10.1590/198380422016241107

Vieira, A. G., \& Waischunng, C. D. (2018). A atuação do psicólogo hospitalar em Unidades de Terapia Intensiva: a atenção prestada ao paciente, familiares e equipe, uma revisão da literatura. Revista da SBPH, 21(1), 132-153. http://pepsic.bvsalud.org/pdf/rsbph/v21n1/v21n1a08.pdf

Submetido: $26 / 11 / 2019$

Aprovado: 01/06/2020 